\title{
Analysis on Role of Network Technology Information Integration in the Agricultural Development of Beijing-Tianjin-Hebei
}

\author{
R.L.MIAO, X.C.WEI, Y.Y.HOU \& J.MENG \\ Beijing Institute of Science and Technology Information, Beijing, China
}

\begin{abstract}
Beijing-Tianjin-Hebei has integrity and indivisibility in agricultural industrial structure. However, as the development of information technology, the number of agricultural websites in BeijingTianjin-Hebei area increasingly rises, as a result, it gets quite difficult to get agricultural technological information. To realize effective utilization of scientific and technological information resources about agriculture in Beijing-Tianjin-Hebei area, we need to integrate agricultural technological information, adopt unified information dissemination standards, establish relations between information released by agricultural information institutes and agricultural research institutes, thus to improve the extent of sharing of agricultural information resources. With the objective to promote the agricultural development in Beijing-Tianjin-Hebei area, this paper discusses the role of agricultural technological information resources integration in the agricultural development of Beijing-Tianjin-Hebei.
\end{abstract}

KEYWORD: Beijing-Tianjin-Hebei; agriculture; scientific and technological information; integration; role

\section{INTRODUCTION}

Beijing-Tianjin-Hebei has integrity and indivisibility in agricultural industrial structure. In 2012, the gross regional product of Beijing-Tianjin-Hebei was 5.72612 trillion yuan, Beijing, Tianjin and Hebei were respectively 1.7801 trillion, 1.288518 trillion and 2.6575 trillion. Among which, the agricultural industry were respectively 15.03 billion, 17.154 billion and 318.67 billion, the contribute rate were respectively $0.84 \%, 1.33 \%$ and $12 \%$. The agricultural output of Beijing and Tianjin occupied a very low proportion in the regional overall economy, this also reflects the stage in which the economic development of this two areas stay. Due to the huge gap between the low agricultural proportion and the huge demand for agricultural products in Beijing and Tianjin, additional agricultural products need to be imported from areas outside Beijing and Tianjin, for Hebei, which surrounds Beijing and Tinajin and has absolute advantages in geographical location, it has sufficient conditions to become the most important import base of agricultural products. To promote the agricultural development in Beijing-Tianjin-Hebei, we need to effectively link the technology with the market through agricultural technological information. However, as the development of information technology, the number of agricultural websites in Beijing-Tianjin-Hebei area increasingly rises, as a result, it gets quite difficult to get agricultural technological information. To realize effective development and utilization of scientific and technological information resources about agriculture in Beijing-Tianjin-Hebei area, we need to integrate agricultural technological information, adopt unified information dissemination standards, establish relations between information released by agricultural information institutes and agricultural research institutes, thus to improve the extent of sharing of agricultural information resources. With the objective to promote the agricultural development in Beijing-Tianjin-Hebei area, this paper discusses the role of agricultural technological information resources integration in the agricultural development of Beijing-Tianjin-Hebei.

\section{STATUS OF AGRICULTURAL TECHNOLOGICAL INFORMATION RESOURCES INTEGRATION IN BEIJING- TIANJIN-HEBEI}

Since the 1990s, as the development of network and digital technology, a construction boom of agricultural science and technology information has been set off in China, websites of governments at all levels, including the state, province, city, county or even towns, as well as agriculture-related websites 
with the purpose of profits were established. These agricultural information websites mainly provide agricultural policies, agricultural practical technology, market and agricultural investment projects and other information for regional agricultural development. Additionally, there are many websites established by agricultural research institutes and educational institutes to serve scientific research. Although the quantity of agricultural websites in Beijing-Tianjin-Hebei area is large, the status is that the information resources posted in the websites are quite limited and updated very slowly.

\subsection{Too many websites}

To search online with "agricultural information network" as the keyword, thousands of agricultural information websites in Beijing-Tainjin-Hebei can be found. However, due to mechanism, interest and other reasons, these websites have not established any unified standard system in aspect of information acquisition standard and search channels, service scope of information resources, category of information resources and so on, there is not an exchange system among data on different websites. Information resources on different agricultural websites lack for necessary integration, thus information can not be shared, much inconvenience are brought to query about agricultural information.

\subsection{Quite limited information}

As the development of network and digital technology, Beijing-Tianjin-Hebei strengthened the construction of agricultural information systems dispersed in various regions, as well as linkage and collaboration between agricultural information dissemination agencies, for example, the agricultural scientific research branches and the central administration institutes jointly established and shared agricultural information resource. Agricultural information resources of different types are distributed on different agricultural websites in different forms, for development and use of users. However, information resources can not be mutually shared by websites established by government departments at all levels, as well as agriculturerelated enterprises and agricultural scientific research and educational departments. Therefore, although the quantity of websites in Beijing-TianjinHebei area is large, information resources on agricultural websites are seriously limited.

\subsection{Serious repeated construction phenomenon}

In the agricultural production process, the information resources published by various agricultural agencies do provide a lot of help for agricultural production, yet the complex information flow disables the vast agricultural information users to find out the information they needed quickly. Due to mechanisms, interest and other reasons, various agricultural information portal websites in BeijingTainjin-Hebei act in their own ways, no unified standard system has been formed in aspect of information acquisition standard, search channels, service scope of information resources and category classification of information resources, etc, there is no exchange system among data on different websites, reconstruction phenomenon exists seriously in information resources, the same information may appear on different agricultural information portal websites or the same information appears on the same portal agricultural information website.

\subsection{Non-uniform standard}

Computer and communications technology promoted the development of the information society, significant changes have appeared in forms and types of agricultural information resources. In addition to the resources with paper as the carrier, there are also many agricultural information resources with different storage media, various formats and types on the network. Such as the selfbuilt database reflecting agricultural characteristics of different regions, technology database established by the third-party platform to reflect the agricultural dynamics, database sharing the agricultural scientific data and database storing agricultural literature, etc. Different agricultural information dissemination institutes describe agricultural information resources with different formats and types in different ways, as a result, data description standard is non-uniform, the fields used are not standardized, these are not conductive to the sharing of information resources.

Additionally, different databases provide different search interfaces to users, further, there is no communications and exchange among resources between different databases, all these problems have led to difficulties in the sharing of information resources.

\section{ROLE OF AGRICULTURAL TECHNOLOGICAL INFORMATION RESOURCES INTEGRATION}

Agricultural technological information includes numerical data, knowledge data, laws and regulations data, news report data, directory data, image data, multimedia data and software data, etc. Different from traditional agriculture, the agricultural development in Beijing-Tianjin-Hebei area depends on development and promotion of agricultural new technologies, it requires technology, 
capital, talent and intelligence support. However, in such a big data era, discovering and effectively use scientific and technological information from a large quantity of agricultural technological information resources is a quite complex system engineering.

Integration of agricultural technological information resources is one of the most effective ways to solve the status of too many websites and quite limited information in aspect of agricultural technological information in Beijing-Tianjin-Hebei.

\subsection{Reducing impacts caused by asymmetric information}

Due to the different development progress of various areas in Beijing-Tianjin-Hebei in aspect of information technology and agricultural technological information integration, coupled with the different development emphasis in different areas, a serious imbalance phenomenon exists in the construction of agricultural technological information resources, repeated construction and limited information exist in the information platform, as a result, technological information resources can not be effectively shared. For specific information, read the following sections. (1)Uneven distribution of agricultural technological information resources .Impacted by network infrastructures or local economic and technological strength, economically developed or talent-intensive areas have sufficient scientific and technological achievements and information resources, while the regional network information resources in remote areas are significantly insufficient. (2)Uneven progress in agricultural technological information resources construction. Areas or industries with sufficient resources and capital develop faster and achieve more achievements in construction of agricultural technological information resources. While some areas or industries with dispersed information resources and insufficient capital develops quite slow in construction of network technological information resources.

Development and infrastructures status in different areas are affected by many factors, the gaps can not be eliminated in a short term, however, effectively integrate the agricultural technological information resources, publish, spread and publicize such resources according to a unified standard can, to a certain extent, reduce and eliminate the uneven status of technological achievements and information resources caused by uneven economic development in Beijing-Tianjin-Hebei.

\subsection{Reducing the impact caused by uneven contents quality of agricultural technological information}

In the network environment, the agricultural technological information resources are characterized by mutuality, openness and information duplicability. Most information published does not receive quality review, some scientific data lacks of rigorous and systematic verification through scientific experiments, some can not accurately reflect the inherent laws of scientific research activities. There is not any proper quality control system, the standards used are not unified or even there is no standard as basis at all, or the information technology, information processing method based are relatively backward, all these may result in the improper accuracy, reliability and comparability of network technological information. For specific information, see the following contents.

(1)From the aspect of form, such issues are reflected in the diversity of specific information carrier forms, complexity of information distribution form, flexibility of dissemination forms, nonstandard information editing, insufficient quality control, non-uniform information publishing ways, etc.

(2)From the aspect of contents, such issues are reflected in the huge gaps between significance of different technological information, incomplete and improper description about technological information can affect the coherent value of the information, for example, some information is published after intrinsic and standard scientific experiments or verification, thus they have a high level of confidence, while some are just technological explorations or speculations, or some one-sided view about a certain issue.

In the network environment, such a difference in quality of technological information tends to have progressive characteristics, the difference of quality increases as the improved information technology, increased information quantity, acceleration of information dissemination and constantly improved information demands of users. However, if we effectively integrate the agricultural technological information resources, publish, disseminate and publicize according to unified standards, we can effectively reduce and eliminate the technological information with different qualities caused by diversified information carriers and contents quality in Beijing-Tianjin-Hebei area within a certain range.

\subsection{Reducing impact of non-standard management on agricultural technological information resources}

In the network environment, dissemination forms and contents of agricultural technological information are becoming increasingly diverse. However, no effective information publishing and management constraining system has been formed in Beijing-Tianjin-Hebei, there is also no unified quality specification standards. Compared with developed countries, the agricultural technological 
information resources in Beijing-Tainjin-Hebei are still in a scattered, non-networking, independent processing state, most databases are established in different formats, those which established according to international and domestic standards are quite limited in quantity, most databases only provide the technological information resources themselves, yet not reveal the information sources, processing states and other quality background information.

If we effectively integrate the technological information resources, improve the compatibility of the resource databases, realize real network sharing and utilization, publish and disseminate information resources according to a unified standard, we can effectively reduce and eliminate the impacts caused by non-standard management on technological achievement information resources.

\section{CONCLUSION}

The integration of agricultural technological information in Beijing-Tianjin-Hebei area is a complex system engineering, the government, universities, scientific research institutes, enterprise, market, capital and all other factors need to play their own roles in the scientific and technological development system. Facing the massive scientific and technological information in the modern society, as the popularization of Internet and other information transmission tools, information can be rapidly spread throughout the whole world, therefore, only through integration of agricultural technological information resources, could we reduce the asymmetry of agricultural technological information, improve the quality of technical information contents, solve the difficulties in acquisition of technological information and the non-standard technological information resources management and other problems, thus to promote the effective publishing and dissemination of agricultural technological information, maximize the agricultural development interests in BeijingTianjin-Hebei area.

\section{REFERENCES}

[1] SM ITS R, KUHLMANN S. The rise of systemic instruments in innovation policy. International Journal of Foresight and Innovation Policy, 2004, 1:4-30.

[2] JEREMY HOWELLS. Intermediation and the role of intermediaries in innovation. Research Policy, 2006, 35:715-728.

[3] Xiang Hong, Cao Ruzhong, Innovative thinking about promotion of scientific and technological information work in China, Science and Technology Management Research, 2012, (3); 1-3

[4] Song Yanhong, Discussion on participation of nonprofit science and technology institutes in implementation of government compretitive intelligence, Enterprise Science and Technology \&Development, 2012 (4):1-4.

[5] Sun Ying, Application of science and technology information in basic public services, Electronic Test, 2013(6):249-250.

[6] Zheng Xiaoping, Review of the National Innovation System, Scientific Management Research, 2006(8):1-5

[7] SHAH ID YUSUF. Intermediating knowledge exchange between universities and businesses. Research Policy, 37:1167-1174. 